27 | Printemps 2006

CRITIQUE D'ART 27

\title{
Robert Malaval
}

\section{Christophe Cherix}

URL : http://journals.openedition.org/critiquedart/1224

DOI : $10.4000 /$ critiquedart. 1224

ISBN : 2265-9404

ISSN : 2265-9404

Éditeur

Groupement d'intérêt scientifique (GIS) Archives de la critique d'art

Édition imprimée

Date de publication : 1 avril 2006

ISBN : 1246-8258

ISSN : 1246-8258

\section{Référence électronique}

Christophe Cherix, «Robert Malaval », Critique d'art [En ligne], 27 | Printemps 2006, mis en ligne le 13 février 2012, consulté le 20 avril 2019. URL : http://journals.openedition.org/critiquedart/1224 ; DOI : $10.4000 /$ critiquedart. 1224

Ce document a été généré automatiquement le 20 avril 2019.

Archives de la critique d'art 


\title{
Robert Malaval
}

\author{
Christophe Cherix
}

\section{RÉFÉRENCE}

Robert Malaval, Paris : Palais de Tokyo : Paris-Musées, 2005

1 «Pourquoi montrer un artiste qui s'est suicidé en 1980 dans un lieu consacré aux artistes émergents?» est l'une des interrogations placées en préambule du catalogue de l'exposition du Palais de Tokyo dédiée au travail de Robert Malaval. A lire les préfaciers Nicolas Bourriaud et Jérôme Sans -, la réponse tient au fait que, pour démontrer le «dynamisme de la scène artistique française », il faut " assumer et promouvoir sa propre histoire, avant de pouvoir la partager avec le reste du monde ». Les exemples de Paul Thek et de Bas Jan Ader sont convoqués et «la capacité de l'art américain à réécrire périodiquement le récit de ses origines en fonction de l'évolution de l'actualité » est donnée en modèle.

2 Passons le fait que Bas Jan Ader, bien qu'établi à Los Angeles, soit hollandais et qu'à l'instar de Paul Thek, sa reconnaissance posthume soit essentiellement due aux travaux de galeries et d'institutions européennes. Ce qui pose problème est l'idée, présentée pourtant comme une évidence, que l'Histoire serait sujette à une périodique réécriture «en fonction de [...] l'actualité ». L'affirmation est questionnable: d'une part, elle présuppose que l'histoire de la période en question fasse l'objet d'un certain consensus ; d'autre part, elle présente le risque de mettre le spectateur contemporain dans un rapport de simple consommation vis-à-vis des œuvres d'art qui l'ont précédé. Dès le départ, le catalogue de la "première exposition historique » du Palais de Tokyo place donc tout lecteur quelque peu critique sur ses gardes: au final, la publication ne lui épargnera pas, comme c'était malheureusement à craindre, les poncifs habituels sur la « culture rock» et les simplifications abusives de l'histoire de l'art. Ce dernier apprend par exemple, toujours dans la préface, que «Malaval est l'un des seuls artistes des années 1960-1970, avec Richard Hamilton ou Dan Graham, à avoir réellement intégré la 
culture rock dans son travail, au-delà de l'anecdote ou de la simple iconographie ». Hormis le côté très péremptoire d'une telle affirmation, quel ne sera pas l'étonnement du lecteur que de constater que l'ouvrage l'entraîne précisément dans un flot quasi continu d'anecdotes et d'images?

Le premier texte, sous la plume de Jean-François Bizot, fait figure de prologue non paginé. Son caractère «à vif »- il fut publié pour la première fois en 1980, soit peu de temps après la disparition de Malaval - s'en trouve mis en exergue. Toutefois, au-delà des émotions très honorables qu'il véhicule encore aujourd'hui, il se réduit quelque vingtcinq ans après sa rédaction à un mélange de propos rapportés, de considérations d'ordre général et d'assertions parfois discutables (par exemple : "Nicolas de Staël, le dernier grand abstrait, s'est suicidé pour ne pas se répéter »). Vient alors la préface que nous avons évoquée, suivie dans la foulée d'un commentaire de Marc Sanchez sur l'exposition elle-même. La manifestation avait la particularité de prendre place à la fois au Palais de Tokyo et dans le cadre de la Biennale de Lyon (une salle était pour partie consacrée à Malaval). Sanchez nous apprend que cette seconde partie de la manifestation était intitulée La Couleur pure. "Le tout respire le plaisir de peindre et le bonheur transparent " explique un commissaire aux accents subitement tellement matissiens qu'il semble en oublier l'étrange association qu'il suscite avec La Couleur seule : l'expérience du monochrome, une exposition organisées par le même Musée d'art contemporain de Lyon en 1988. C'est à Vincent Pécoil qu'il revient de conclure le cahier de textes. Un joli titre - «Blanche generation ", une demie traduction libre du disque de Richard Hell Blank Generation - pour un essai intelligent qui tente une mise en perspective historique du travail de Malaval. La juxtaposition d'une photographie de l'artiste en chemise à fleurs, alité et lisant une bande dessinée, et d'un portrait peint par Adrian Piper sous l'emprise du LSD est à mon sens le meilleur moment iconographique de la publication.

Enfin, une section d'images, reproduisant plus d'une centaine d'œuvres et ponctuée de paroles de l'artiste, vient clore la publication. Tant les fonds noirs, sur lesquels viennent se positionner textes et documents, la faible qualité de la photolithographie (notamment en ce qui concerne les peintures pourtant intéressantes réalisées à l'aide de paillettes) que la taille des caractères des titres rendent cependant cette partie de la publication quelque peu rébarbative. Toutefois, cette impression est contrebalancée par la diversité du matériel retenu et par le mélange des médiums proposé (peinture, dessin, sculpture, performance, photographie) : le livre donne alors enfin la mesure de l'œuvre de Malaval en orientant notamment le lecteur sur des pièces peu connues, à l'instar des très étonnants dessins à l'encre de Chine du début des années 1960. 